\title{
Effects of stimulus-response uncertainty on watchkeeping performance and choice reactions'
}

RICHARD A. KULP, HUMRRO DIVISION NO. 2 (ARMOR) EARL A. ALLUISI, UNIVERSITY OF LOUISVILLE

The present study was conducted to assess the effects of $S-R$ uncertainty on performance in watchkeeping and typical type-b choice-reaction situations. The assessment was based in part on measurements of S-R compatibility effects in the two performance conditions. Four levels of $S-R$ uncertainty $(1,2,3$ and 4 bits/S-R event) were combined factorially with two levels of S-R compatibility (high and low) and the two kinds of tasks (watchkeeping and choice-reaction); $12 \mathrm{Ss}$ were assigned at random to each of the 16 conditions. A matrix of lights was used as stimuli in the choice-reaction condition; Ss monitored the matrix for a 1-h duration in the watchkeeping condition. In both tasks, $S$ s responded by pressing a corresponding key after the presentation of a stimulus or "critical signal." Reaction time (RT) was found to be an increasing linear function of $S-R$ uncertainty in both tasks, and the effects of $S-R$ compatibility were essentially identical in the two. However, choice reactions were significantly faster than watchkeeping responses, and the rate of gain of information in watchkeeping was greater than in the comparable choice-reaction situations. The results are interpreted as supporting the hypothesis that watchkeeping differs from the simpler choice-reaction task principally in presenting an additional source of (temporal) uncertainty for information processing.

Hick's (1952) application of information theory to cholce-reaction tasks stimulated several subsequent studies. For example, Hyman (1953) and Gregg (1954) obtained data which supported Hick's report that disjunctive reaction time is an increasing linear function of the amount of information transmitted per S-R event (Ht). Under certain conditions, however, a null rate of gain of information has been found; 1.e., a slope constant of zero has been obtained in the linear function that relates reaction time and Ht (cf., Klemmer \& Muller, 1953; Leonard, 1954; Mowbray \& Rhoads, 1959; Mowbray, 1960). The differences seem to have been explained at least in part by other investigators who demonstrated that the rate of gain of information varies as a function of the S-R compatibility of the ensemble employed in the cholce-reaction task (Brainard et al, 1962; Fitts \& Switzer, 1962; Alluisi et al, 1964).

The results of a recent study of the relative effects of signal density and regularity on watchkeeping performance Indicate that response time is an increasing linear function of the temporal uncertainty of the critical signal in the watchkeeping task. This suggests that there may be a close similarity between choice-reaction and watchkeeping tasks, at least insofar as they both employ the same general conditions of stimulation.

The present experiment was designed to investigate the effects of S-R uncertainty on both watchkeeping and choice-reaction tasks and, thereby, to measure the relative effects of $S-R$ uncertainty on reaction time (RT) in the two kinds of tasks.

\section{METHOD}

Four levels of stimulus-response uncertainty (1, 2,3 , and 4 bits/S-R event) were combined factorially with two levels of S-R compatibility (high and low)
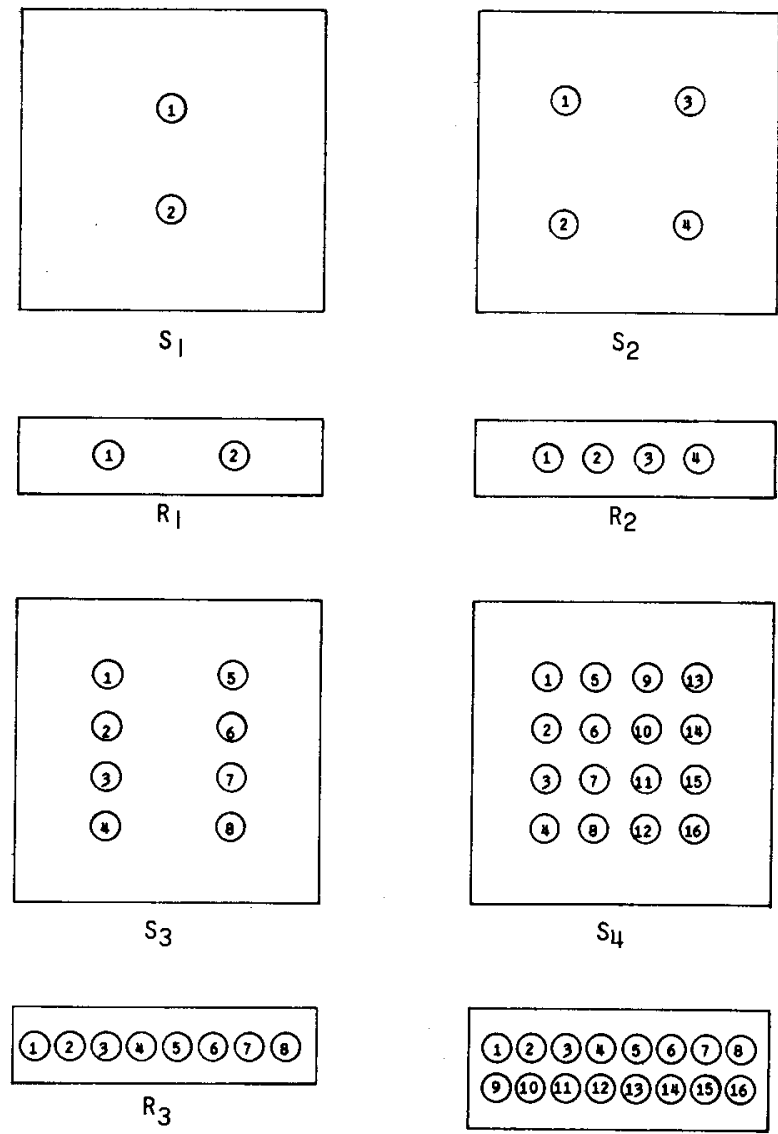

(1)(2)(3)(4)(5)(7)(B) (9)(10)(11) (13) (14)(13) (16)

$R_{4}$

Fig. 1. Stimulus panels $s_{1}, s_{2}, s_{3}$, and $s_{4}$ were used in both high and low S-R compatibility ensembles; response panels $R_{1}$, $R_{2}, R_{3}$, and $R_{4}$ were used to form ensembles of low S-R compatibility, whereas response panels that were isomophic with the stimulus panels were used to forn the high S-R compatibility ensembles. 
and two kinds of tasks (watchkeeping and choicereaction) to provide 16 different experimental conditions. Twelve Ss were assigned at random to each of the 16 conditions.

\section{Stimulus-response Ensembles}

As shown in Fig. 1, four $S-R$ ensembles were constructed to provide a relatively low level of S-R compatibility at each of the four levels of S-R uncertainty. This was accomplished by arranging the stimulus and associated response elements or positions systematically, but differently, on the stimulus and response panels. On the other hand, ensembles with high S-R compatibility were created by making the stimulus and response elements isomorphic in spatial arrangement (cf., Deininger \& Fitts, 1955); in these conditions, both stimulus and response panels were arranged like the stimulus panels shown in Fig. 1 .

The stimuli for the four levels of S-R uncertainty $(1,2,3$, and 4 bits/S-R event) were lights numbered 1 and 2, 1 through 4,1 through 8 , and 1 through 16 , for the four levels, respectively. The lights were mounted on a vertically placed panel; they were arranged spatially as is shown in Fig. 1 on 1 in. centers. The clouded lenses were $5 / 8$ in. in diameter and the height of the Arabic numeral centered on each lens was $7 / 32$ in. The brightness as measured with a Spectra Brightness Spot Meter was $150 \mathrm{ft}-\mathrm{L}$.

\section{Subjects}

A total of 192 male volunteers served as Ss; 12 Ss were randomly assigned to each of the 16 experimental conditions. All Ss were enlisted men assigned to duty at the U.S. Army Armor Center, Fort Knox, Kentucky. Each $S$ was free of visual defects according to Army standards. The median age was 21 years, with a range of 18 to 34 years.

\section{Apparatus}

The critical signal that $S$ was asked to detect and respond to was a $0.05 \mathrm{sec}$ flash of one of the lights on the display panel. The timing of the flash was provided by a Hunter timer (Model III-A). After a signal, $S$ had $8 \mathrm{sec}$ during which to respond, and if he falled to respond during that interval he was scored with a missed signal. If he responded at any other time, $S$ was scored with a false response.

The $12 \mathrm{~V}$ dc bulbs used on the stimulus panels were located approximately at eye level 28 in. directly in front of the seated $S$. The stimuli were well above threshold and easily visible to $S$. The response required of $\mathrm{S}$ was his pressing a correspondingly numbered pushbutton when he detected a critical signal. The response buttons were mounted on a horizontally placed panel; they were arranged on 1 in. centers according to the spatial requirements of the two $S-R$ compatibility conditions discussed previously (see Fig. 1).

In the watchkeeping task, the signals were presented by means of a Gerbrands variable-interval programmer that used punched $16-\mathrm{mm}$ film as a programming tape; the timer was connected in series with a simple $20 \mathrm{~V}$ dc relay timing circuit. The correct signal detections, missed signals, and false responses of $S$ were recorded on an EsterlineAngus operations recorder (voltage type, Model AW). A Standard Electric timer (Type S1) was used in measuring RT to correct signal detections (in 0.01 sec).

Eight different programming tapes were used to control the time of occurrence of the critical signals; each employed a different random order of intersignal intervals (ISIs), but in all cases 24 signals were presented to each $\mathrm{S}$ during his $1 \mathrm{~h}$ watch. The distribution of ISIs approximated the right-hand half of a normal distribution with a coefficient of variation of 1.00 and a mean ISI of $150 \mathrm{sec}$. This distribution has been found to be essentially identical to that initially employed by Mackworth (1950; for additional details, see Smith (1961); Chinn \& Alluisi (1964)). Further variation in the order of ISIs was obtained by use of 12 different starting positions per tape; thus, each $S$ was exposed to a different specific order of ISIs in the watchkeeping task.

In the choice-reaction task, the programming of signals and signal duration was controlled by use of two Hunter timers (Model III-A) connected in series with a simple $20 \mathrm{~V}$ dc relay timing circuit. A warning signal (buzzer) was presented 2 sec before the stimulus. Experimental sessions lasted about $10 \mathrm{~min}$ in the choice-reaction part of the study, with stimuli presented at a rate of about 4 per min.

\section{Procedure}

Each $S$ was tested individually in a $6 \times 8 \mathrm{ft}$ experimental booth that was illuminated by a single $60 \mathrm{~W}$ overhead incandescent bulb. When seated in the experimental booth facing the display, each $S$ was given a general description of either the watchkeeping or the cholce-reaction task and its application to man-machine systems. He was instructed to respond to the detection of a numbered signal by pressing the correspondingly numbered pushbutton with his preferred hand as quickly as possible and then to return his hand to a response pad located immediately in front of him (and between his body and the response panel). In addition, $\mathrm{Ss}$ in the cholcereaction conditions were told that the warning buzzer would precede the critical signal by a couple of seconds. Each $\mathrm{S}$ was shown the stimulus and given three practice trials before the actual experimental trials began, in order to eliminate any confusion 
that he might have had with regard to his task. Additional details of the methodology are given elsewhere (Kulp, 1966).

\section{RESULTS}

Missed signals and RTs were separately analyzed. Since no more thatn two false responses were made in any of the 16 experimental conditions, no analysis of the false response data was deemed appropriate.

\section{Missed Signals}

No signal was missed in either the high or low S-R compatibility conditions of the choice-reaction task. However, in the high compatibility watchkeeping task, the percentage of signals missed ranged from 2.7 to 11.8 , with a mean of 6.3 . In the low compatibility conditions of the watchkeeping task, the percentage of signals missed ranged from 2.0 to 4.2, with a mean of 2.9 . The difference was not statistically significant $(t=1.343, d f=47, p>.05)$.

\section{Response Tìme}

The median RT was computed from each S's 24 responses (the median was used as the measure of choice because of the skewed distributions typically obtained with RT data). The median RTs were then averaged within each of the 16 experimental conditions; these data are shown in Fig. 2.

The summary of an analysis of variance of these

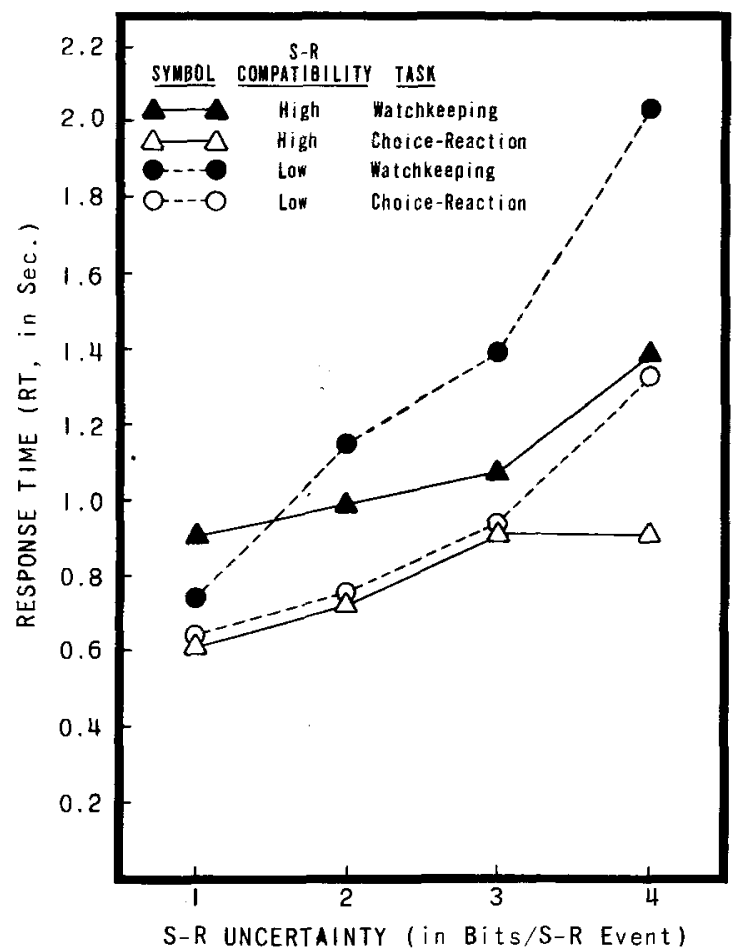

Fig. 2. Reaction time as a function of stimulus-response uncertainty at four levels of task complexity.
Table 1.

Summary of an Analysis of Variance of Median Reaction Times

\begin{tabular}{lrrr} 
Source & df & MS & F \\
\hline Task Complexity (TC) & 3 & 2.54 & $70.56^{* * *}$ \\
Watchkeeping vs Choice-Reaction & 1 & 23.67 & $657.50^{* * *}$ \\
High vs Low Compotibility in Watchkeeping & 1 & 5.66 & $157.22^{* * *}$ \\
High vs Low Compotibility in & & & \\
Choice-Reoction & 1 & 3.34 & $92.78^{* * *}$ \\
& & & \\
S-R Uncertainty (U) & 3 & 4.20 & $111.67^{* * *}$ \\
Overall slope (UL) & 1 & 11.70 & $10.73^{*}$ \\
Deviations (Dev. UL) & 2 & 0.18 & 2.09 \\
TC X U & 9 & 0.420 & $11.67 * *$ \\
Between groups slope (BGS) & 3 & 1.09 & $12.67^{* *}$ \\
Deviation s (Dev. BGS) & 6 & 0.086 & \\
Within Ss & 176 & 0.036 & -- \\
Total & 191 & -1 & - \\
\hline
\end{tabular}

${ }^{*} p<.05, * * p<.01, * * * p<.001$

data is shown in Table 1. The major sections of the analysis indicate that both main effects (Task Complexity and S-R Uncertainty) were significant sources of variation, as was their interaction (TC by $U$ ).

In order to understand more clearly the nature of the Task Complexity (TC) effects, a further partitioning by orthogonal components was computed. The first comparison was between watchkeeping and choice-reaction tasks; the difference is statistically significant. This is interpreted as an indication that in a choice-reaction task information processing time is significantly faster than in a watchkeeping task. The remaining two orthogonal comparisons were between the two levels of $S-R$ compatibility in each of the two tasks (i.e., high vs low compatibility in the watchkeeping and choice-reaction situation); the difference was statistically significant in each of the two cases. Thus, S-R compatibility effects appear to operate similarly in both watchkeeping and choice-reaction situations.

A further analysis of the S-R Uncertainty (U) factor and the interaction ( $\mathrm{TC}$ by $\mathrm{U}$ ) by means of an extended trend test (Grant, 1956) revealed a significant overall linear slope (UL) for the functions of Fig. 2. The overall linear slope accounted for $97 \%$ of the variation due to the main effect of the $U$ factor, and the overall deviations from this slope were not statistically significant when tested against the deviations from group slopes (Dev BGS).

The extended analysis of the TC by $U$ interaction revealed significant linear components of variation among the four group slopes (BGS). That is to say, $86 \%$ of the $\mathrm{TC}$ by $\mathrm{U}$ interaction variance was accounted for by differences among the linear trends in the profiles of factor $U$ at the different levels of factor TC. There was no appropriate error term for testing the statistical significance of the deviations from group slopes (Dev BGS). 


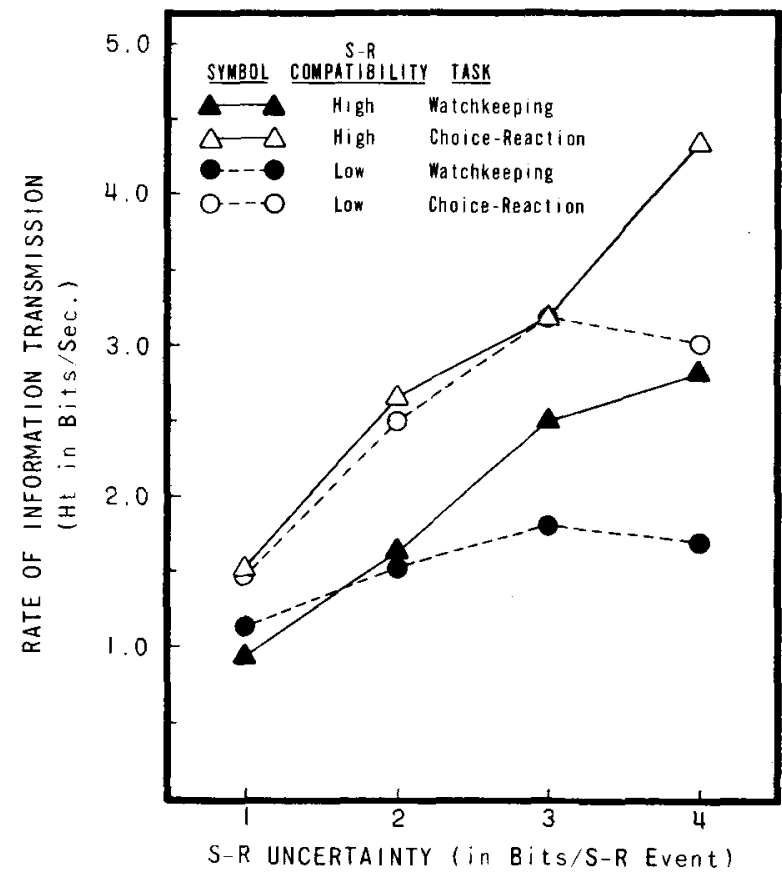

Fig. 3. Average rate of information transmission as a function of stimulus-response uncertainty at four levels of task complexity.

\section{Rate of Information Transmission}

The average amount of information transmitted under each experimental condition was computed from a single matrix containing the pooled data of all Ss (for method, see Garner \& Hake (1951); Attneave (1959)). Each of these 16 estimates was then divided by the corresponding average RT to provide an estimate of the average rate of information transmission in each experimental condition. These average rates of information transmission are shown in Fig. 3 as a function of S-R uncertainty for each of the four levels of task complexity employed.

The rate of information transmission appears to be linearly related to $S-R$ uncertainty up to 3 bits/ S-R event, beyond which the high S-R compatibility conditions (coded with triangles and solid lines) tend to maintain this relation, whereas the transmission rates of the low S-R compatibility conditions (coded with circles and broken lines) tend to decrease. The greater rate of information transmission with high S-R compatibility, especially at the highest S-R uncertainty level of 4 bits/S-R event, which was first reported for choice-reaction situations by Fitts and Seeger (1953), appears equally applicable to watchkeeping tasks.

\section{DISCUSSION}

This study had as its stated principal objective the measurement of the relative effects of S-R uncertainty on $\mathrm{RT}$ in the two kinds of tasks employed. The results indicated that the effects of S-R com- patibility on performance in a watchkeeping task were essentially identical to those previously demonstrated in choice-reaction situations (e.g., first shown by Fitts \& Seeger, 1953).

From a broader perspective, however, the present study may be viewed as having been concerned with the extent to which the watchkeeping task (with its additional temporal uncertainty) may be represented as essentially identical to the choice-reaction task. That is to say, the study can be viewed as having been concerned with the question of how different forms of uncertainty combine to affect performance -both temporal and S-R uncertainty in watchkeeping, but only $S-R$ uncertainty in the choice-reaction task.

If man's performance in both watchkeeping and choice-reaction tasks is assumed to be one of information processing, and if a psychophysical function can be determined for this performance, then it should be possible to predict the manner in which the different sources of uncertainty combine to affect performance. One such prediction (cf., Alluisi, 1966; Smith et al, 1966) is that the contributions of different sources of uncertainty are linearly additive. If this is so, then RT or information processing time in the watchkeeping task should increase linearly as $S-R$ uncertainty increases, but at a faster rate than in the choice-reaction task; this appears to have been the result obtained (see Fig. 2).

Specifically, in terms of RT to correct signal detections, the results indicated that: (1) choicereactions are significantly faster than watchkeeping RTs; (2) RT is a linear increasing function of S-R uncertainty for both tasks combined over both levels of S-R compatibility; (3) the slopes of the four task compatibility functions differed significantly, with the rate of gain of information being greater for watchkeeping than for choice-reactions in the low compatibllity conditions (slope constants of 1.433 and 0.274 , respectively), as well as in the high compatibility conditions $(0.216$ and 0.111 , respectively); and (4) the high and low compatibility differed significantly, with the slope constant being greater in the latter condition (0.167 and 0.602 , respectively).

The second and fourth of these findings have been demonstrated repeatedly to hold for choice-reaction tasks (Hick, 1952; Crossman, 1953; Hyman, 1953; Gregg, 1954; Brainard et al, 1962; Fitts \& Switzer, 1962; Alluisi et al, 1964). The first and third of these findings extend these demonstrations to include watchkeeping tasks as well; in addition, they support the prediction that the contributions of different sources of uncertainty are linearly additive (cf., Alluisi, 1966; Smith et al, 1966). They do this by demonstrating that the effect of increasing $S-R$ uncertainty on processing time is greater in a watchkeeping task (with its added temporal uncertainty) than in the choice-reaction task. Finally, the parsimonious conclusion appears to be that watch- 
keeping and reaction tasks do not differ qualitatively, but rather differ in predictable, quantitative ways that depend on the total (temporal, spatial, and other) uncertainty presented in the whole S-O-R paradigm. References

Alluisi, E. A. Attention and vigilance as mechanisms of response: Comments on Professor Adams' paper. In E. A. Bilodean (Ed.), Acquisition of skill. New York: Academic Press, 1966. Pp. 201213

Alluisi, E. A., Strain, G. S., \& Thurmond, J. B. Stimulus-response compatibility and the rate of gain of information. Psychon. Sci. $1964,1,111-112$.

Attneave, F. Applications of information theory to psychology: $A$ summary of basic concepts, methods, and results. New York: Holt, Rinehart and Winston, 1959.

Brainard, R. W., Irby, T. S., Fitts, P. M., \& Alluisi, E. A. Some variables influencing the rate of gain of information. $J$. exp. Psychol, , 1962, 63, 105-110.

Chinn, R. McC., \& Alluisi, E. A. Effect of three kinds of knowledge-of-results information on three measures of vigilance performance. Percept. mot. skills, 1964, 18, 901-912.

Deininger, R. L., \& Fitts, P. M. Stimulus-response compatibility, information theory, and perceptual-motor performance. In $\mathrm{H}$. Quastler (Ed.), Information theory in psychology. Glencoe, Illinois: Free Press, 1955.

Fitts, P. M., \& Switzer, G. Cognitive aspects of information processing: I. The familiarity of S-R sets and subsets. $J$. exp. Psuchol., 1962, 63, 321-329.

Grant, D. A. Analy sis-of-variance tests in the analysis and comparison of curves, Psychol. Bull., 1956, 53, 141-154.

Garner, W. R., \& Hake, H. W. The amount of information in absolute judgements. Psychol. Rev., 1951, 58, 446-459.

Gregg, L. W. The effects of stimulus complexity on discrimination response. J. exp. Psychol., 1954, 48, 289-297.

Hick, W. E. On the rate of gain of information. Quatt. J. exp. Psychol., 1952, 4, 11-26.
Hyman, R. Stimulus information as a determinate of reaction time. J. exp. Psychol., 1953, 45, 188-196.

Klemmer, E. T., \& Muller, P. F. The rate of handling information: Key pressing responses to light patterns. USAF HFORL memo. Rep., 1953, No. 34.

Kulp, R. A. Effects of stimulus-response uncertainty on performance of a watchkeeping task. Unpublished master's thesis, University of Louisville, 1966.

Leonard, J. A. The effects of partial advance information. Med. Res. Coun. Appl.Psychol. Unit (G. Brit.) Rep., 1954, No. 217/54.

Mackworth, N. H. Researches on the measurement of human performance. Merl. Res. Coun. (G. Brit.) Spec. Rep. Ser., 1950 No. 268 .

Mowbray, G. H., \& Rhoades, H. Y, on the reduction of choice reaction times with practice. Quart. J. exp. Psychol, 1959. 11, 16-23.

Mowbray, G. H. Choice reaction times for skilled responses. Quart. J. exp. Psychol., 1960, 12, 193-202.

Smith, R. P. The effects of signal density and signal variability on the efficiency of human vigilance. Unpublished doctoral dissertation, Emory University, 1961.

Smith, R. P., Warm, J. S., \& Alluisi, E. A. Effects of temporal uncertainty on watchkeeping performance. Percept. \& Psychophys., 196ü, 1, 293-299.

\section{Note}

1. Supported in part by the U.S. Army Medical Research and Development Command, Department of the Army, under Contract No. DA49-193-MD-2567, "Behavioral Effects of Infectious Diseases." This paper is based on a master's thesis submitted by the senior author at the University of Louisville; the thesis was prepared under the direction of the junior author. An abridged report of this research was presented by the senior author at the 58th annual meeting of the Southern Society for Philosophy and Psychology, April, 1966, New Orleans, La.

(Accepted for publication July 17, 1967.) 